\title{
Organophosphorus-induced extrapyramidal intermediate syndrome in an adolescent suicide attempt survivor
}

\author{
Sumantra Sarkar, Madhumita Nandi, Rakesh Mondal' ${ }^{1}$, Sandip Kumar Mandal \\ Department of Pediatric Medicine, Institute of Postgraduate Medical Education and Research and Seth Sukhlal Karnani Memorial Hospital, \\ Kolkata, 'Department of Pediatric Medicine, North Bengal Medical College and Hospital, Darjeeling, West Bengal, India
}

\section{ABSTRACT}

The victims of organophosphorus (OP) pesticide poisoning usually present with acute cholinergic crisis, due to the inhibition of the enzyme acetylcholinesterase. Any neurological complication in the form of intermediate syndrome is rare and its presentation with extrapyramidal symptoms is even rarer. The authors report such a case in a 12-year-old adolescent girl, who survived a near lethal suicidal attempt.

Key words: Extrapyramidal, intermediate syndrome, organophosphorus poisoning, suicide

\section{Introduction}

Organophosphate $(\mathrm{OP})$ pesticides used for agricultural purpose are common suicidal agents. The victims normally present with acute cholinergic crisis due to the inhibition of the enzyme acetylcholinesterase. A presentation of late onset neuropathy, due to long-term occupational exposure to OP, has also been described. ${ }^{[1]}$ An intermediate syndrome that occurs between the early cholinergic crisis and late onset neuropathy is rare and often missed. ${ }^{[2,3]}$ This syndrome usually occurs 24 to 96 hours following ingestion of OP and presents with clinical symptoms like weakness in the neck flexor muscles, proximal limb muscles, respiratory muscles, and depressed tendon reflexes. Extrapyramidal symptoms (EPS), such as, tremor, rigidity or dystonia, as part of the intermediate syndrome, are very rare ${ }^{[4]}$ The authors report a case of Intermediate Syndrome with extrapyramidal symptoms due to organophosphorus poisoning in a 12-year-old adolescent girl, who survived a near lethal suicidal attempt.

\begin{tabular}{|l|l|}
\hline \multicolumn{2}{|c|}{ Access this article online } \\
\hline Quick Response Code: & Website: \\
\hline & www.ruralneuropractice.com \\
\cline { 2 - 2 } & \\
\hline$\square$ & DOI: \\
\hline
\end{tabular}

\section{Case Report}

A 12-year-old adolescent girl, in a suicide attempt, consumed an organophosphorus pesticide, Fenthion, and developed profuse frothing, lacrimation, and vomiting soon after. She was taken to a nearby rural hospital and treated with gastric lavage, atropine, antibiotics, and intravenous fluid. There was no history of fever, seizures, jaundice, bleeding manifestation, head trauma, delayed developmental milestones or any neurocognitive decline. Her family history was also noncontributory. She was referred to our institute when no significant improvement was noted.

Following admission, treatment was continued with atropine and other supportive measures with close monitoring. Four days after admission, she developed loss of speech, tremor and intermittent jerky movements, in all four limbs with extension of neck. On day 7 she became unconscious and examination revealed a Glasgow Coma Scale (GCS) score E2V2M2. Her vital signs included: A blood pressure of 100/60 $\mathrm{mmHg}$; heart rate of $94 /$ minute; respiratory rate of $45 /$ minute; and temperature of $38.5^{\circ} \mathrm{C}$. She was shifted to Intensive Care anticipating respiratory failure. She started recovering with supportive management and responded to verbal stimuli on day

Address for correspondence:

Dr. Sumantra Sarkar, Flat B1, Jibantaru Apartment, North Jagtala (near Batamore), Mahestala, Kolkata - 141, West Bengal, India. E-mail: sumantra.com@gmail.com 
12. She regained full alertness during the next two days. The tremor and intermittent jerky movements persisted. In addition she developed rigidity, mask-like face, and intermittent hypertonia [Figure 1]. The laboratory studies were unremarkable. Examination of her cerebrospinal fluid (CSF) was normal. Magnetic resonance imaging (MRI) of the brain, done on day 15 , revealed no abnormality. Her speech returned partially on day 16 and it was slow, with slurring and a monotonous tone. She started walking slowly with short steps on day 17. She was discharged on day 18 and referred to the Department of Psychiatry for evaluation. At follow-up after three months, all her signs and symptoms had completely reversed.

\section{Discussion}

Organophosphorus is a commonly used suicidal agent, as it is an easily found pesticide in the rural agricultural-based communities. However, reports on acute and long-term complications in adolescent suicide-attempt survivors following OP ingestion are scarce in literature. Four types of OP-induced neurological syndromes had been described. ${ }^{[5]}$ These are: (1) Cholinergic crisis/Type 1 syndrome; (2) Intermediate syndrome/Type 2 syndrome; (3) Organophosphate-Induced Delayed Polyneuropathy (OPIDN); and (4) Chronic Organophosphate-Induced Neuropsychiatric Disorder (COPIND). Among them, cholinergic crisis is the most common following exposure to larger doses of OP compounds. Only a few patients might develop the 'Intermediate Syndrome', a term coined by Senanayeke in 1987. ${ }^{[6]}$ Interestingly, all the OP compounds do not produce the intermediate syndrome. Ingestion of a few specific OP compounds like diazinon, methylparathion, methamidaphos, fenthion, and ethylparathion, among others, might result in such a distinctive neurological complication, in a dose-dependent manner. ${ }^{[4]}$ The clinician should be alert and anticipate such neurological sequelae if the victim consumes these specific OP compounds.

Our patient initially presented with a cholinergic crisis, but later on she developed features of extrapyramidal involvement such as temporary loss of speech, muscle tone abnormalities, tremor and rigidity. She was diagnosed as having the intermediate syndrome with extrapyramidal manifestations. The reversibility of the symptoms with supportive management establishes a transient phase of the syndrome. The extrapyramidal symptoms, which occur rarely as a part of the intermediate syndrome, are thought to be due to the inhibition of acetylcholinesterase in the human

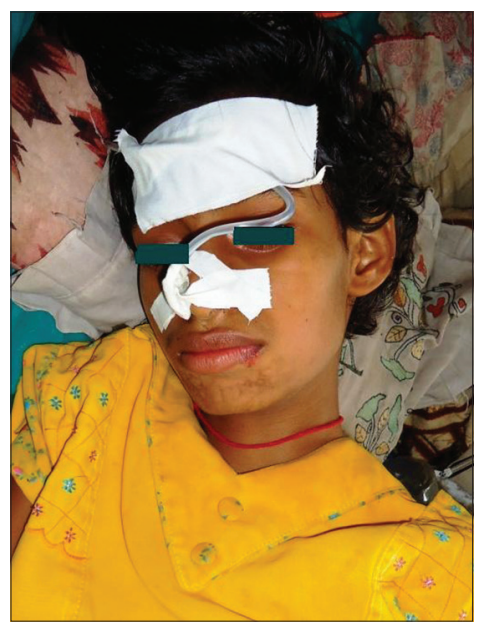

Figure 1: Victim of organophosphorus poisoning showing mask-like facies

extrapyramidal areas. ${ }^{[4,5]}$ Increased susceptibility of the basal ganglia nuclei to the toxic products, in the absence of efficient detoxification pathways, may also be responsible. ${ }^{[7]}$ Atropine or pralidoxime are ineffective in treating this condition. ${ }^{[8]}$ Although abnormal signal intensities in the region of basal ganglia have been demonstrated in brain MRIs for some patients, most cases are reported to have normal neuroimaging. ${ }^{[3]}$ The brain MRI was normal in our patient.

The reason for presenting this case is that the intermediate syndrome following OP poisoning is an uncommon neurological complication and it might go unnoticed if the clinician has not included this in the differential diagnosis. Moreover, the intermediate syndrome presenting with extrapyramidal symptoms is extremely uncommon in children. Although it is reversible in most cases, a few children might develop features of respiratory muscle weakness progressing into respiratory failure. As it is a very common mode of suicide in rural areas, identification of the syndrome and timely referral for appropriate supportive care can be life saving.

\section{References}

1. Savage EP, Keefe TJ, Mounce LM, Heaton RK, Lewis JA, Burcar PJ. Chronic neurological sequelae of acute organophosphate poisoning. Arch Environ Health 1988;43:38-45.

2. Leon-S FE, Pradilla G, Vesga E. Neurological effects of organo-phosphorous pesticides. BMJ 1996;313:690-1.

3. Senanayake N, Sanmuganathan PS. Extrapyramidal manifestation complicating organophosphorus insecticide poisoning. Hum Exp Toxicol 1995;14:600-4.

4. Sedgwick EM, Senanayake N. Pathophysiology of the intermediate syndrome of organophosphorus poisoning. J Neurol Neurosurg Psychiatry 1997;62:201-2.

5. Singh S, Sharma N. Neurological syndromes following organophosphate poisoning. Neurol India 2000;48:308.

6. Senanayake N, Karalliede L. Neurotoxic effects of organophosphorous insecticides. N Engl J Med 1987;316:761-3. 
7. Steventon GB, Heafield MT, Waring RH, Williams AC. Xenobiotic metabolism in Parkinson's disease. Neurology 1989;39:883-7.

8. Burillo-Putze G, Hoffman RS, Howland MA, Duenas-Laita A. Late administration of pralidoxime in organophosphate (fenitrothion) poisoning. Am J Emerg Med 2004;22:327-8.
How to cite this article: Sarkar S, Nandi M, Mondal R, Mandal SK. Organophosphorus-induced extrapyramidal intermediate syndrome in an adolescent suicide attempt survivor. J Neurosci Rural Pract 2014;5:276-8.

Source of Support: Nil. Conflict of Interest: None declared. 